\title{
Do incarcerated male juvenile recidivists differ from first- time offenders on self-reported psychopathic traits? A retrospective study
}

European Journal of Criminology $1-19$

(C) The Author(s) 2018 Reprints and permissions: sagepub.co.uk/journalsPermissions.nav DOI: I0.II77//4773708|8772774 journals.sagepub.com/home/euc

@SAGE

\section{Pedro Pechorro}

University of Minho, Portugal

\section{Teresa Braga}

University of Minho, Portugal

\section{James V. Ray}

University of Central Florida, USA

\section{Rui Abrunhosa Gonçalves}

University of Minho, Portugal

\section{Henrik Andershed}

School of Law, Psychology and Social Work, Örebro University, Örebro, Sweden

\begin{abstract}
The current study analyzed the relation between recidivism and self-reported psychopathic traits, more specifically the callous-unemotional, impulsivity, and narcissism dimensions of the psychopathy construct. The Antisocial Process Screening Device - Self-Report (APSD-SR) and other selfreport instruments independently measuring the three different dimensions of psychopathy (that is, Inventory of Callous-Unemotional Traits, Barratt Impulsiveness Scale-II, Narcissistic Personality-13) were completed by a sample of incarcerated male juvenile offenders $(N=244)$ who were retrospectively classified as recidivists versus non-recidivists. The only statistically significant relation found between recidivism and self-reported psychopathic traits after controlling for age and socioeconomic status was with the impulsivity dimension of the APSD-SR. Additionally, results showed that recidivism was associated with alcohol use but not with drug use or crime seriousness.
\end{abstract}

\section{Corresponding author:}

Pedro Pechorro, School of Psychology, University of Minho, Campus de Gualtar, Braga, 47I0-057, Portugal. Email: ppechorro@gmail.com 


\section{Keywords}

Juvenile delinquency, psychopathic traits, recidivism

In the criminological literature, recidivism has been generally defined as the relapse of an individual into criminal behavior after receiving a correctional intervention (Maltz, 1984; Payne, 2007; Zara and Farrington, 2016). For most juveniles, delinquent behavior is an ephemeral, normal part of adolescence. However, for a small group of adolescents, offending patterns are marked by high rates of recidivism (see Blumstein, Cohen et al., 1986, and Piquero et al., 2003, for reviews). Several criminological theories, in particular developmental and life-course theories, have taken these different patterns of criminal offending into account (see Farrington, 2003, for a review). Moffitt's (1993) developmental taxonomy, for instance, proposes that the age-crime curve, characterized by an increase of offending in early adolescence, a peak in late adolescence, and dropping afterwards, conceals two qualitatively distinct categories of offenders. The life-coursepersistent offenders are a small group who exhibit antisocial behavior at young ages and persist in offending at high rates over their life course owing to the interaction between their neuropsychological difficulties and the environment and cumulative and contemporary consequences. The other group is the adolescence limited, which comprises those whose offending is temporary and acute up to adolescence as a result of a maturity gap during adolescence and mimicry of their life-course-persistent peers, who appear to have achieved a more mature status (that is, material goods, independence of family).

Understanding why or, at best, which factors increase the probability of individuals reverting to their criminal path is of great interest to researchers, clinicians, and policy makers. That is, identifying variables related to recidivism can aid in the development of effective intervention efforts (Loeber and Farrington, 1998) along with informing risk assessment (Andrews and Bonta, 2010). One important risk factor for recidivism is psychopathy. Psychopathy is a multidimensional construct that consists of affective (for example, lack of remorse, callousness), interpersonal (for example, narcissism, manipulativeness), and behavioral (for example, impulsivity, irresponsibility) components (Hare, 2003), and springs from genetic and environmental factors (for example, Fontaine et al., 2010; Larsson et al., 2006). Interestingly, like the high-rate offending group identified by Moffitt (1993), individuals with high psychopathic traits have been linked to an early involvement in criminal activities, persistent offending, and more serious and injurious crimes (for example, Loeber et al., 2001; Murrie et al., 2004; Pechorro et al., 2014; Vitacco et al., 2007). The similarities between high-rate offenders and the behavioral characterizations of psychopathy have supported suggestions that they are one and the same (Lynam, 1996) or that psychopathic traits may define a subgroup of children within the persistent early starter offender group (Frick and Ellis, 1999). Indeed, empirical findings have also lent support to this conclusion. Piquero et al. (2012) found that a high-rate chronic trajectory revealed higher psychopathy scores (compared with the non-offender, low adolescence-peaked, very low-rate chronics, and high adolescence-peaked trajectories) and the most chronic and frequent offender trajectories had the highest levels of psychopathy. 
Several measures of psychopathic traits have been developed within crime-related research and contexts. The Psychopathy Checklist (PCL-R; Hare, 2003) is a clinical assessment tool of psychopathy that has been used to assess the risk of criminal recidivism among adults. The downward extension of psychopathy to youth led to the development of the Psychopathy Checklist: Youth Version (PCL:YV; Forth et al., 2003). In terms of predicting recidivism, research has systematically shown that the PCL:YV is at least moderately related with recidivism, supporting its predictive validity to appraise the risk of juvenile reoffending (for example, Edens et al., 2007; Olver et al., 2009; Schwalbe, 2007). However, limitations of the PCL:YV abound in terms of its practical use because it requires extensive training and administration time as well as collateral information reviews (for example, institutional records). Self-report measures have been introduced to help overcome some of these practical concerns, although there is skepticism regarding the use of self-report measures in forensic and criminal justice areas (Kroner and Loza, 2001; Lilienfeld and Fowler, 2007). Although several self-report measures of psychopathic traits have been developed, research evaluating their predictive utility in forensic settings is scant. A meta-analysis found that less than one-third of the studies examined the predictive utility of self-report measures, compared with the 29 that examined the PCL:YV (Asscher et al., 2011). In the current study we analyzed the relation of two widely used measures of psychopathy with regard to juvenile recidivism: the Antisocial Process Screening Device (APSD; Frick and Hare, 2001), and the Inventory of Callous-Unemotional Traits (ICU; Essau et al., 2006; Kimonis et al., 2008). Additionally, we examined two measures that independently assess different dimensions of psychopathy: the Barratt Impulsiveness Scale version 11 (BIS-11; Patton et al., 1995; Stanford et al., 2009) and the Narcissistic Personality Inventory-13 (NPI-13; Gentile et al., 2013). We focused on callous-unemotional (CU) traits, narcissism, and impulsivity, because these traits tap into the three psychopathic factors - affective, interpersonal, and impulsive/irresponsible - most often linked and more consensually to children and adolescents (for example, Feilhauer and Cima, 2013). Next, we briefly review research on the relationship between these measures and juvenile recidivism and antisocial behaviors.

\section{Research on the APSD and recidivism}

One of the most widely used self-report measures of psychopathic traits among youth is the APSD. It was modeled after the PCL:YV (Forth et al., 2003) and was originally designed to capture a similar two-factor structure (that is, impulsive/conduct problems [I/CP] and callous-unemotional [CU]; Frick and Hare, 2001). Some findings suggest, however, a three-factor structure that also includes a narcissism factor (for example, Dadds et al., 2005; Vitacco et al., 2003).

The usefulness of the APSD in predicting various antisocial outcomes was recently examined in a sample of detained girls (Colins et al., 2017). The results showed that the APSD total score was not a significant predictor of either violent or nonviolent offending after controlling for past offenses, aggression, and alcohol/drug use. Nevertheless, studies have generally found less evidence for the predictive validity of psychopathy among girls (for example, Edens et al., 2007; Schmidt et al., 2006). Using male or mixed gender 
samples, other studies have found that the APSD total score was related to certain types of recidivism, such as general but not violent reoffending (Salekin, 2008), violent and weapons-related but not general recidivism (Douglas et al., 2008), and reoffending conceptualized as a dichotomous but not as a continuous variable (Boccaccini et al., 2007). The impulsivity subscale was most consistently related to recidivism while the CU subscale was unrelated to antisocial outcomes across the aforementioned studies.

These overall mixed results may be linked to the unstable factor structure of the APSD dimensions, with some studies providing stronger evidence for two factors (for example, Colins et al., 2014) and others for three factors (for example, Fritz et al., 2008), and their low internal consistency particularly with regard to the CU subscale (for example, Poythress et al., 2006). The CU subscale has been criticized for its limited number of items and for having only three response options (for example, Loney et al., 2003). Another possible explanation is that some studies examined the bivariate relation between psychopathic traits and recidivism whereas others included covariates such as antisocial variables. Meta-analyses have identified antisocial characteristics such as age of criminal onset (Cottle et al., 2001), criminal history, aggression, and alcohol/drug abuse (Assink et al., 2015) as the strongest predictors of juvenile persistent offending. Thus, the inclusion of these variables in models assessing APSD predictive utility may have led to the inconsistent results across studies.

\section{Research on the ICU and recidivism}

The ICU was developed to provide a more comprehensive assessment of CU traits and overcome some of the psychometric limitations of the six-item APSD CU subscale. CU traits have been linked to a subgroup of antisocial youth characterized by a lack of remorse, callousness, and diminished emotional responsivity, who tend to engage in more severe, aggressive and stable antisocial behaviors (see Frick et al., 2014, and Frick and White, 2008, for reviews). Additionally, children with severe conduct problems and CU traits show an increased risk of developing psychopathy in adulthood (for example, Barry et al., 2000; Frick and White, 2008).

A recent study examined the relationship between the ICU and recidivism, and the results are promising. Specifically, Kimonis et al. (2016) followed up a sample of 227 juvenile justice-involved boys. Results indicated an inverse relationship between time to re-offend and scores on the ICU. Additionally, higher CU traits were associated with a greater number of prior criminal charges. The predictive utility of the ICU has also been found among young men, as its scores were related to future arrests, and female offenders, predicting prison misconduct, even after controlling for well-known risk factors including other psychopathic traits (Thomson et al., 2015; Kahn et al., 2013). Furthermore, several analyses of the criterion validity of the ICU point to significant associations between its scores and antisocial outcomes such as aggression and delinquency (for example, Byrd et al., 2013; Feilhauer et al., 2012; Kimonis et al., 2008; Ray et al., 2016).

\section{Research on the NPI, BIS and recidivism}

The NPI and BIS are self-report measures of narcissism and impulsivity, respectively. Although these measures were not developed to assess psychopathy or individual 
psychopathic traits, they do assess characteristics that tap into the interpersonal and impulsive/irresponsible factors of this multidimensional construct. The relationship between the NPI, the BIS, and juvenile recidivism has been somewhat limited. However, these self-report measures have been examined with regard to their criterion validity for other antisocial outcomes. The children's version of the NPI (Narcissistic Personality Inventory for Children; Barry et al., 2003) was found to be a significant predictor of selfreport delinquency (Barry et al., 2007) and peer-nominated relational aggression (Golmaryami and Barry, 2010) for adolescents who had withdrawn from school. More recently, Pechorro, Gentile et al. (2016) found significant associations between the NPI, two of its short forms (NPI-16 and NPI-13), and age of criminal onset, crime seriousness, conduct disorder symptoms, alcohol abuse, and cannabis use. As for the BIS, one of the most widely used self-report measures of impulsivity, a systematic review was conducted on literature examining its psychometric proprieties. Approximately half of the 21 studies analyzed BIS-11 criterion-related validity, concluding that its scores were positively associated with a wide variety of risk behaviors such as alcohol consumption and aggression (Vasconcelos et al., 2012).

\section{The current study}

In summary, research on psychopathic traits as risk factors for recidivism is a promising and important area of research, but additional research is required. In particular, few studies have examined the relation between self-report measures of psychopathy and recidivism. Additionally, the findings are equivocal in terms of the predictive utility of the specific domains of psychopathy as captured by these self-report measures among the few studies that exist. Proven their predictive validity, self-report measures of psychopathic traits may hold practical advantages over the time-consuming clinical rating scales often used for risk assessments in forensic settings. The main aim of the present study was to analyze which component of psychopathy, based on scores from the APSD-SR, ICU, BIS-11, and NPI-13, best distinguished between juvenile offenders who were identified as recidivists and those who were identified as non-recidivists among a sample of Portuguese incarcerated male juvenile delinquents. To our knowledge this is the first study to examine the topic of youth recidivism in Portugal from a retrospective perspective, more specifically the relationship between recidivism and the construct of psychopathy among Portuguese juvenile offenders, and one of the very few among south European youth.

\section{Method}

\section{Participants}

Male inmates $(N=244)$ from the eight, nation-wide juvenile detention centers managed by the Portuguese Ministry of Justice voluntarily agreed to participate in the current study. Incarceration in a juvenile detention center is the most severe dispositional option of courts in accordance with the Portuguese juvenile justice legislation. In Portugal, juvenile law applies to 12 to 15 year olds, and offenders can be treated as adults beginning at age 16 . Seven of the detention centers are considered low to medium security and 
one is considered maximum security. The maximum security facility is exclusively used for youths tried as adults (11.5 percent of participants came from this facility).

Participants ranged in age from 12 to 20 years $(M=16.67$; $\mathrm{SD}=1.43)$, were primarily from an urban background (92.2 percent), and were composed of white Europeans (53.3 percent), black Africans (19.7 percent), mixed race South Americans (19.6 percent), and members of other ethnic minorities (7.4 percent). About 83.2 percent were Portuguese nationals and 16.8 percent were foreigners. The participants, on average, became involved in crime at an early age $(M=11.32$ years, $\mathrm{SD}=2.23$ years $)$, were detained prior to the age of $16(M=15.46$ years, $\mathrm{SD}=1.32$ years $)$, and had been sentenced to an average of 21 months in detention $(M=20.87$ months, $\mathrm{SD}=6.69$ months $)$. The majority (87.9 percent) of the sample were convicted of having committed serious and/or violent crimes (for example, homicide, robbery, assault, rape).

\section{Instruments}

The APSD (Frick and Hare, 2001) self-report version (APSD-SR; Caputo et al., 1999) is a multidimensional 20-item measure designed to assess psychopathic traits in adolescents. It was modeled after the Psychopathy Checklist (Forth et al., 2003; Hare, 2003). Each item is scored on a three-point ordinal scale ranging from 'Never' to 'Often'. The total score, as well as each dimension score, is obtained by adding the respective items. Recent studies reported three main factors: callous-unemotional, narcissism, and impulsivity. Higher scores indicate higher psychopathic traits. The Portuguese version of the APSD-SR (Pechorro, Hidalgo et al., 2016) was used. The internal consistency for the current study, estimated by Cronbach's alpha, was: APSD-SR total $=.78$; callous-unemotional $=.66$; impulsivity $=.51$; and narcissism $=.71$.

The ICU (Essau et al., 2006) self-report is a 24-item scale designed to assess callous and unemotional traits in youth derived from the CU subscale of the APSD (Frick and Hare, 2001). Each item is scored on a four-point scale ranging from 'Not at all true' to 'Definitely true'. Scores are calculated by reverse-scoring the positively worded items and then summing the items to obtain a total score. Using confirmatory factor analysis it was possible to identify three independent factors, namely: callousness, unemotional, and uncaring. All items also loaded onto a general CU factor (Kimonis et al., 2008). Higher scores indicate an increased presence of CU traits. The Portuguese version of the ICU (Pechorro, Ray et al., 2016; Pechorro et al., 2017) was used. The internal consistency for the current study, estimated by Cronbach's alpha, was: ICU total = .90; callousness $=.87$; uncaring $=.85$; and unemotional $=.86$.

The BIS-11 (Patton et al., 1995; Stanford et al., 2009) is a 30-item self-report questionnaire designed to measure impulsiveness. Each item is scored on a four-point ordinal scale ranging from 'Rarely/never' to 'Almost always/always'. The BIS-11 contains six subscales corresponding to the six first-order factors, which converge into three secondorder factors, namely: (1) attentional impulsiveness (attention and cognitive instability subscales); (2) motor impulsiveness (motor and perseverance subscales); and (3) nonplanning impulsiveness (self-control and cognitive complexity subscales). The total score, as well as each subscale score, is obtained by adding the respective items, but some items are scored in reverse order to avoid a response bias. The items are summed 
and the higher the BIS-11 scores, the higher the impulsiveness level. A Portuguese version of the BIS-11, especially adapted for use with adolescents, was used (Pechorro et al., 2015; Pechorro, Ayala-Nunes et al., 2016). The internal consistency for the current study, estimated by Cronbach's alpha, was: BIS-11 total $=.84$; attention $=.79$; cognitive instability $=.61$; motor $=84$; perseverance $=.52$; self-control $=.79$; and cognitive complexity $=.68$. Only the three dimensions of the BIS-11 with the highest internal consistency were used in the present study.

The NPI-13 (Gentile et al., 2013) is a short version derived from the original Narcissistic Personality Inventory (Raskin and Terry, 1988). It consists of 13 pairs of statements, in which one is considered to confirm an attitude of narcissism and the other is not (coded 1 and 0 , respectively). Respondents are instructed to indicate the item that best describes them. Gentile et al. (2013) developed the NPI-13 specifically to maintain the three-factor structure: leadership/authority (LA), grandiose/exhibitionism (GE), and entitlement/exploitativeness (EE). Higher scores indicate higher levels of narcissism. The Portuguese version of the NPI-13 was used (Pechorro, Gentile et al., 2016). The internal consistency for the current study, estimated by the Kuder-Richardson coefficient (that is, alpha for dichotomous items), was NPI-13 total $=.80 ; \mathrm{LA}=.73 ; \mathrm{GE}=.68$; and $\mathrm{EE}=.61$.

The Sellin-Wolfgang Index of Crime Seriousness (ICS; Wolfgang et al., as cited in White et al., 1994) was used to assess crime seriousness in the current study. This measure guided the delinquency seriousness classification of the official court reports. Level 0 consists of no delinquency. Level 1 consists of minor delinquency committed at home, such as stealing minor amounts of money from mother's purse. Level 2 consists of minor delinquency outside the home, including shoplifting something worth less than $€ 5$, vandalism and minor fraud (for example not paying bus fare). Level 3 consists of moderately serious delinquency, such as any theft over $€ 5$, gang fighting, carrying weapons, and joyriding. Level 4 consists of serious delinquency, such as car theft and breaking and entering. Level 5 consists of having performed at least two of each of the behaviors in level 4.

A questionnaire was constructed to describe the socio-demographic and criminal characteristics of the participants. It included questions about participants' age, ethnic group, rural versus urban origin, years of schooling completed, socioeconomic status (SES), parents' marital status, nationality, taking of psychiatric medication, age of first transgression, age of first problem with the law and age of first incarceration in a juvenile detention center, number of criminal cases, number of crimes, criminal diversity, cannabis use, cocaine/heroin use, and alcohol abuse (these last three coded as five-point ordinal variables). SES was measured by a combination of the parents' level of education and profession, appropriate to the Portuguese context (Simões, 2000).

\section{Procedures}

Authorization to assess youths was obtained from the General Directorate of Reintegration and Prison Services - Ministry of Justice (DGRSP-MJ). The detainees from the eight existing Portuguese juvenile detention centers that admit convicted male youths were informed about the nature of the study and asked to voluntarily participate. The 
participation rate was approximately 92 percent. Not all young people agreed or were able to participate; reasons for this included refusal to participate ( 5 percent), inability to participate owing to not understanding the Portuguese language ( 2 percent), and inability to participate owing to security issues (1 percent). Information was obtained from multiple sources, including self-reports and institutional files (for example, taking of psychiatric medication). The questionnaires were administered in an appropriate setting and it was stressed that there were no right or wrong answers. After the assessment, official criminal data for the entire country were obtained from a database of the DGRSP-MJ. This database was used to retrospectively code the recidivism status of each participant (dependent variable). Participants with at least one official prior conviction registered in the database since they were 12 years old were considered recidivists, whereas participants with no previous official convictions since they were 12 years old were considered first-time offenders/non-recidivists (coded $0=$ non-recidivist; $1=$ recidivist).

The data were analyzed using SPSS v24 (IBM SPSS, 2016). Binary logistic regression was used to test unique associations between the predictor variables (for example, dimensions of psychopathic traits) and the dependent variable (recidivism status). The first block of each binary logistic regression model was used to control for moderator variables (for example, age, SES). Point-biserial correlations and partial point-biserial correlations controlling for moderator variables (for example, age, SES) were used to analyze the association between dichotomous variables and scale variables (that is, between scale scores and recidivism). Correlations were considered low if below .20, moderate if between .20 and .50, and high if above .50. ANOVAs, Kruskal-Wallis tests and chi-square tests were used to compare groups when the dependent variables were scale, ordinal, or nominal, respectively. Effect sizes partial eta squared $\left(\eta_{\mathrm{p}}{ }^{2}\right)$, eta squared $\left(\eta^{2}\right)$ and phi $(\Phi)$ were used (Leech et al., 2015).

\section{Results}

About 83.2 percent of the participants were recidivists $(n=203)$ and 16.8 percent were non-recidivist/first-time offenders $(n=41)$. Statistically significant differences between recidivists and non-recidivists were found in terms of age $\left(F=12.153, p \leq .01, \eta_{\mathrm{p}}{ }^{2}=.05\right)$ and SES $\left(\chi_{\mathrm{KW}}^{2}=6.710, p \leq .01, \eta^{2}=.03\right)$, with recidivists being older and having lower SES. No significant differences between recidivists and non-recidivists were found in terms of ethnicity $\left(\chi^{2}=6.334 ; p=.10, \Phi=.16\right)$, taking of psychiatric medication $\left(\chi^{2}=\right.$ $.001 ; p=.97, \Phi=.00)$, rural versus urban origin $\left(\chi^{2}=.015 ; p=1.00, \Phi=.01\right)$, and nationality $\left(\chi^{2}=9.622 ; p=.53, \Phi=.20\right)$.

Table 1 presents the point-biserial correlations for recidivism status (coded $0=$ nonrecidivist, 1 = recidivist) with self-report measures of psychopathic traits and various antisocial/criminal variables (for example, alcohol use, drug use, crime seriousness). Also presented are the partial point-biserial correlations between recidivism and these variables controlling for age and SES. Interestingly, the APSD-SR impulsivity dimension obtained the only significant association with recidivism after controlling for age and SES.

Table 2 displays the hierarchical binary logistic regression coefficients for recidivism status, entering age and SES as covariates in the first step, the dimensions of the APSD-SR as predictors in the second step, and finally the number of crimes committed and alcohol 
Table I. Point-biserial correlations and partial point-biserial correlations with recidivism controlling for age and SES.

\begin{tabular}{|c|c|c|c|c|}
\hline & $r_{\mathrm{pb}}$ recidivism & $p$ value & $\begin{array}{l}\text { Partial } r_{\mathrm{pb}} \\
\text { recidivism }\end{array}$ & $p$ value \\
\hline APSD-SR total & .05 & $p=.41$ & .10 & $p=.15$ \\
\hline APSD-SR CU & -.05 & $p=.48$ & .00 & $p=.95$ \\
\hline APSD-SR Imp & .12 & $p=.06$ & .16 & $p=.02$ \\
\hline APSD-SR Nar & .04 & $p=.50$ & .07 & $p=.29$ \\
\hline ICU total & .02 & $p=.73$ & .06 & $p=.38$ \\
\hline ICU Callousness & -.02 & $p=.76$ & .01 & $p=.90$ \\
\hline ICU Uncaring & .06 & $p=.39$ & .09 & $p=.19$ \\
\hline ICU Unemotional & .03 & $p=.60$ & .06 & $p=.40$ \\
\hline BIS-II total & .01 & $p=.89$ & .03 & $p=.64$ \\
\hline BIS-II Attention & -.08 & $p=.24$ & -.05 & $p=.44$ \\
\hline BIS-II Motor & .03 & $p=.70$ & .07 & $p=.31$ \\
\hline BIS-II Self-control & .07 & $p=.27$ & .07 & $p=.31$ \\
\hline NPI-I 3 total & -.03 & $p=.61$ & .00 & $p=.98$ \\
\hline NPI- I 3 LA & .03 & $p=.61$ & .06 & $p=.34$ \\
\hline NPI-I3 GE & -.07 & $p=.28$ & .04 & $p=.56$ \\
\hline NPI-I3 EE & -.04 & $p=.50$ & .03 & $p=.66$ \\
\hline Alcohol & .24 & $p \leq .001$ & .20 & $p=.01$ \\
\hline Cannabis & .11 & $p=.09$ & .07 & $p=.30$ \\
\hline Cocaine/heroin & .06 & $p=.30$ & .03 & $p=.68$ \\
\hline Crime seriousness & .05 & $p=.4 I$ & .04 & $p=.57$ \\
\hline No. criminal cases & .40 & $p \leq .001$ & .36 & $p \leq .001$ \\
\hline No. crimes & .25 & $p \leq .001$ & .25 & $p \leq .001$ \\
\hline Criminal diversity & .24 & $p \leq .001$ & .23 & $p \leq .001$ \\
\hline
\end{tabular}

Notes: $r_{\mathrm{pb}}=$ Point-biserial correlation; APSD-SR $=$ Antisocial Process Screening Device - Self-Report; APSD-SR CU = callous-unemotional dimension; APSD-SR Imp = impulsivity dimension; APSD-SR Nar = narcissism dimension; NPI- I 3 = Narcissistic Personality Inventory-I3; NPI-I 3 LA = leadership/authority dimension; NPI-13 GE = grandiose/exhibitionism dimension; NPI-13 EE = entitlement/exploitativeness dimension.

use variables in the third step. Across all steps, age and SES consistently distinguished between recidivists and non-recidivists; that is, older youths and those with lower SES were more likely to be classified as recidivists. The APSD-SR impulsivity dimension was significant in the 2nd step only, and the number of crimes was significant in the 3 rd step. Youths who had a more extensive history of crime and alcohol use were more likely to be classified as recidivists. Table 2 also displays the regression coefficients for recidivism status entering age and SES as covariates in the first step, the dimensions of the ICU as predictors in the second step, and the number of crimes committed and alcohol use variables in the third and final step. Age and SES were always significant, but none of the ICU dimensions was significant in the 2nd step. In the 3rd step, age and SES remained significant and the number of crimes and alcohol use also distinguished between recidivists and non-recidivists. Those who had a more extensive history of crime and alcohol use were more likely to be classified as recidivists. 
Table 2. Logistic regression coefficients of APSD-SR and ICU predicting recidivism.

\begin{tabular}{|c|c|c|c|c|c|}
\hline & $B$ & SE & Wald & $\operatorname{Exp}(B)$ & $p$ value \\
\hline \multicolumn{6}{|l|}{ APSD-SR } \\
\hline \multicolumn{6}{|l|}{ Ist Step } \\
\hline Age & 0.495 & .138 & 12.823 & 1.640 & $p \leq .001$ \\
\hline SES & -0.840 & .392 & 4.589 & 0.432 & $p=.03$ \\
\hline Constant & -6.050 & 2.253 & 7.212 & 0.002 & $p=.01$ \\
\hline \multicolumn{6}{|l|}{ 2nd Step } \\
\hline Age & 0.504 & .145 & 12.121 & 1.656 & $p \leq .001$ \\
\hline SES & -0.990 & .410 & 5.827 & $0.37 I$ & $p=.02$ \\
\hline $\mathrm{CU}$ & -0.059 & .101 & 0.340 & 0.943 & $p=.56$ \\
\hline Impulsivity & 0.332 & .158 & 4.410 & 1.394 & $p=.04$ \\
\hline Narcissism & 0.011 & .100 & 0.012 & 1.011 & $p=.91$ \\
\hline Constant & -7.233 & 2.532 & 8.158 & 0.001 & $p=.004$ \\
\hline \multicolumn{6}{|l|}{ 3rd Step } \\
\hline Age & 0.371 & .161 & 5.323 & 1.449 & $p=.02$ \\
\hline SES & -1.124 & .457 & 6.039 & 0.325 & $p=.01$ \\
\hline $\mathrm{CU}$ & -0.143 & .113 & 1.597 & 0.867 & $p=.21$ \\
\hline Impulsivity & 0.241 & .183 & 1.743 & 1.273 & $p=.19$ \\
\hline Narcissism & -0.012 & .111 & 0.011 & 0.988 & $p=.91$ \\
\hline No. crimes & 0.268 & .068 & 15.596 & 1.307 & $p \leq .001$ \\
\hline Alcohol use & 0.279 & .168 & 2.755 & 1.321 & $p=.09$ \\
\hline Constant & -6.347 & 2.786 & 5.190 & 0.002 & $p=.02$ \\
\hline \multicolumn{6}{|l|}{ ICU } \\
\hline \multicolumn{6}{|l|}{ Ist Step } \\
\hline Age & 0.495 & .138 & 12.823 & 1.640 & $p \leq .001$ \\
\hline SES & -0.840 & .392 & 4.589 & 0.432 & $p=.03$ \\
\hline Constant & -6.050 & 2.253 & 7.212 & 0.002 & $p=.01$ \\
\hline \multicolumn{6}{|l|}{ 2nd Step } \\
\hline Age & 0.514 & .142 & 13.157 & 1.672 & $p \leq .001$ \\
\hline SES & -0.838 & .396 & 4.479 & .432 & $p=.03$ \\
\hline Callousness & -0.010 & .032 & 0.091 & .991 & $p=.76$ \\
\hline Uncaring & 0.052 & .047 & 1.227 & 1.053 & $p=.26$ \\
\hline Unemotional & 0.016 & .059 & 0.069 & 1.016 & $p=.79$ \\
\hline Constant & -6.890 & 2.435 & 8.005 & .001 & $p=.01$ \\
\hline \multicolumn{6}{|l|}{ 3rd Step } \\
\hline Age & 0.351 & .161 & 4.722 & 1.420 & $p=.03$ \\
\hline SES & -1.013 & .442 & 5.248 & 0.363 & $p=.02$ \\
\hline Callousness & -0.049 & .038 & 1.679 & 0.952 & $p=.19$ \\
\hline Uncaring & 0.033 & .053 & 0.391 & 1.034 & $p=.53$ \\
\hline Unemotional & -0.008 & .071 & 0.012 & 0.992 & $p=.91$ \\
\hline No. crimes & 0.277 & .069 & 16.254 & 1.320 & $p \leq .001$ \\
\hline Alcohol use & 0.366 & .173 & 4.499 & 1.442 & $p=.03$ \\
\hline Constant & -5.75 I & 2.766 & 4.324 & 0.003 & $p=.04$ \\
\hline
\end{tabular}

Notes: APSD-SR = Antisocial Process Screening Device - Self-Report; CU = callous-unemotional; $\mathrm{ICU}=$ Inventory of Callous-Unemotional Traits; SES = socioeconomic status. 
Table 3 presents the hierarchical binary logistic regression coefficients for recidivism status, entering age and SES as covariates in the first step, the dimensions of the BIS-11 as a predictors in the second step, and finally the number of crimes committed and alcohol use variables in the third step. Age and SES were always significant. However, none of the BIS-11 dimensions was significant in the 2nd step. In the 3rd step, age and SES remained significant and the number of crimes and alcohol use also distinguished between recidivists and non-recidivists. Table 3 also presents the regression coefficients for recidivism status, entering age and SES as covariates in the first step, the dimensions of the NPI-13 as predictors in the second step, and the number of crimes committed and alcohol use variables in the third and final step. Again, age and SES were always significant. None of the NPI-13 dimensions was significant in the 2nd step; in the 3rd step, age and SES remained significant and the number of crimes and alcohol use also distinguished between the two groups.

\section{Discussion}

The aim of our study was to determine which components of psychopathy based on several different self-report assessments of psychopathy (that is, APSD-SR, ICU, BIS-11, and NPI-13) distinguished between recidivists and non-recidivists among a sample of incarcerated Portuguese youths. The findings suggest limited utility in any of the different components of psychopathy in identifying recidivists. That is, none of the different components of psychopathy across the different measures distinguished recidivists from non-recidivists once controlling for prior antisocial behavior (that is, alcohol use and number of crimes). As a matter of fact, the only component of psychopathy that distinguished between recidivists and non-recidivists controlling for only age and SES was the impulsivity subscale of the APSD-SR. Thus, based on the findings it seems that past antisocial behavior may indeed be the best indicator of subsequent offending.

Despite clinical measures of psychopathy such as the PCL:YV evidencing good predictive utility (Asscher et al., 2011), self-report measures may have limited utility in predicting recidivism. One explanation for the differences across self-report and clinical assessments in predicting recidivism is that measures such as the PCL:YV include antisocial history, which significantly enhances its utility in predicting recidivism, whereas most self-report measures capture the underlying 'trait-like' aspects of psychopathy. As a matter of fact, research suggests that the behavioral component of the PCL:YV is the best predictor of recidivism (Corrado et al., 2004). It is important to point out that selfreport measures of psychopathy were not designed to be utilized in forensic settings and have largely been developed to assess psychopathic traits in non-incarcerated settings (Brinkley et al., 2001). This may be one explanation for the findings in the current study in terms of different aspects of psychopathy not distinguishing between recidivists and non-recidivists. Another possible explanation is that the restricted range on both recidivism and the psychopathic traits limited the ability to identify any relationships that would exist if they had been measured among the full range of the constructs. To be sure, over 83 percent of the participants in the current sample were classified as recidivists. Thus, future research is needed to examine the relationship between self-report measures of psychopathic traits and recidivism among samples of juvenile offenders with a wider 
Table 3. Logistic regression coefficients of the BIS-I I and NPI-I 3 predicting recidivism.

\begin{tabular}{|c|c|c|c|c|c|}
\hline & $B$ & SE & Wald & $\operatorname{Exp}(B)$ & $p$ value \\
\hline \multicolumn{6}{|l|}{ BIS-I I } \\
\hline \multicolumn{6}{|l|}{ Ist Step } \\
\hline Age & 0.495 & .138 & 12.823 & 1.640 & $p \leq .00 \mathrm{I}$ \\
\hline SES & -0.840 & .392 & 4.589 & 0.432 & $p=.03$ \\
\hline Constant & -6.050 & 2.253 & 7.212 & 0.002 & $p=.01$ \\
\hline \multicolumn{6}{|l|}{ 2nd Step } \\
\hline Age & 0.513 & .143 & 12.911 & I.67| & $p \leq .00 \mathrm{I}$ \\
\hline SES & -0.832 & .397 & 4.383 & 0.435 & $p=.04$ \\
\hline Attention & -0.093 & .072 & 1.651 & 0.911 & $p=.19$ \\
\hline Motor & 0.073 & .055 & 1.728 & 1.075 & $p=.18$ \\
\hline Self-control & 0.040 & .055 & 0.526 & $1.04 \mid$ & $p=.46$ \\
\hline Constant & -6.700 & 2.459 & 7.425 & 0.001 & $p=.01$ \\
\hline \multicolumn{6}{|l|}{ 3rd Step } \\
\hline Age & 0.378 & .159 & 5.606 & 1.459 & $p=.02$ \\
\hline SES & -0.983 & .443 & 4.912 & 0.374 & $p=.03$ \\
\hline Attention & -0.114 & .081 & 1.992 & 0.892 & $p=.15$ \\
\hline Motor & 0.029 & .062 & 0.215 & 1.029 & $p=.64$ \\
\hline Self-control & 0.028 & .063 & 0.189 & 1.028 & $p=.66$ \\
\hline No. Crimes & 0.268 & .068 & 15.612 & 1.308 & $p \leq .001$ \\
\hline Alcohol use & 0.335 & .170 & 3.868 & 1.398 & $p=.05$ \\
\hline Constant & -6.063 & 2.688 & 5.087 & 0.002 & $p=.02$ \\
\hline \multicolumn{6}{|l|}{ NPI-I 3} \\
\hline \multicolumn{6}{|l|}{ Ist Step } \\
\hline Age & 0.495 & .138 & 12.823 & 1.640 & $p \leq .00 \mathrm{I}$ \\
\hline SES & -0.840 & .392 & 4.589 & 0.432 & $p=.03$ \\
\hline Constant & -6.050 & 2.253 & 7.212 & 0.002 & $p=.01$ \\
\hline \multicolumn{6}{|l|}{ 2nd Step } \\
\hline Age & 0.517 & .143 & 13.058 & 1.677 & $p \leq .00 \mathrm{I}$ \\
\hline SES & -0.958 & .412 & 5.408 & 0.384 & $p=.02$ \\
\hline LA & 0.345 & .182 & 3.622 & 1.413 & $p=.06$ \\
\hline GE & -0.092 & .134 & 0.472 & 0.912 & $p=.49$ \\
\hline $\mathrm{EE}$ & -0.259 & .209 & 1.529 & 0.772 & $p=.21$ \\
\hline Constant & -6.159 & 2.329 & 6.991 & 0.002 & $p=.01$ \\
\hline \multicolumn{6}{|l|}{ 3rd Step } \\
\hline Age & 0.353 & .165 & 4.579 & 1.423 & $p=.03$ \\
\hline SES & -1.078 & .452 & 5.677 & 0.340 & $p=.02$ \\
\hline LA & 0.204 & .206 & 0.975 & 1.226 & $p=.32$ \\
\hline GE & -0.032 & .147 & 0.047 & 0.969 & $p=.82$ \\
\hline $\mathrm{EE}$ & -0.244 & .248 & 0.972 & 0.783 & $p=.32$ \\
\hline No. Crimes & 0.259 & .068 & $|4.48|$ & 1.295 & $p \leq .001$ \\
\hline Alcohol use & 0.364 & .174 & 4.397 & 1.439 & $p=.04$ \\
\hline Constant & -5.764 & 2.709 & 4.527 & 0.003 & $p=.03$ \\
\hline
\end{tabular}

Note. BIS-I I = Barratt Impulsiveness Scale version II; NPI-I3 = Narcissistic Personality Inventory- I3; LA = leadership/authority; GE = grandiose/exhibitionism; $\mathrm{EE}=$ entitlement/exploitativeness; $\mathrm{SES}=$ socioeconomic status. 
range of risk of recidivism and psychopathic traits. This will also allow for the testing of the ability of juvenile psychopathic traits to differentiate high-frequency offenders from less frequent offenders. One of the most salient assets of the construct of juvenile psychopathy may involve the identification of a high-rate chronic group of juvenile offenders rather than the distinction between recidivists and first-time offenders.

The findings from the current study are important because they are the first to examine the relationship between recidivism and the different components of psychopathy among a sample of Portuguese youths involved in the juvenile justice system. These findings help to extend our understanding of the use of self-report measures of juvenile psychopathy considering cultural and ethnic differences. Additionally, these findings have important implications for risk assessment in general. In line with previous research, the current study suggests that prior antisocial behavior may be the best indicator for identifying who is at risk of recidivism (Cottle et al., 2001) even beyond psychopathic personality traits. This leads us to conclude that the use of self-reported psychopathic traits in the prediction of recidivism risk should be done with caution.

The current study has important implications for both theory and practice. In terms of which 'core features' of psychopathy are most important for identifying the fledgling psychopath, it seems that our findings are most in line with Lynam's (1996) proposition that the impulsive features are most salient. That is, impulsivity, as assessed by the ASPD, was the psychopathic feature that best distinguished between recidivists and nonrecidivists; although this was no longer significant once prior antisocial behavior was taken into account. It is important to keep in mind, however, that an association with recidivism as measured by official records may not necessarily identify those who will become psychopaths as adults. Thus, although these findings are in line with this notion, more research is needed to directly test and compare which features of psychopathy in adolescence best predict psychopathic traits in adulthood. Our study also has important practical implications. In addition to implications for risk assessment, which were mentioned above, our findings suggest that treatment approaches aimed at simply reducing recidivism may be most effective when they consider reducing the negative consequences of past behavior (for example, cumulative continuity; Caspi et al., 1987), particularly for those who evince the impulsive features of psychopathy (Lynam, 1996).

Although the findings from the current study are important, they should be considered within the context of several limitations. First, and as mentioned above, there was limited variability in the recidivism outcome. The data collection procedures in the current study precluded the use of a more nuanced measure of recidivism (for example, frequency of re-arrest, time to re-arrest). Second, because the current study focused on a sample of incarcerated male juveniles in Portugal, it is not clear how the findings extend to other cultures or ethnicities, and whether they are applicable to female juvenile offenders. Third, the current study was retrospective in terms of identifying the 'outcome'. That is, the methodological approach taken in the current study to distinguish between those classified as recidivists and non-recidivists was based on the criminal history of each participant. Such an approach does not allow for causal conclusions to be drawn, but this limitation is mitigated by studies demonstrating that psychopathic traits are fairly stable in adolescence (for example, Andershed, 2010; López-Romero et al., 2014; Neumann et al., 2011), thus reducing the concern regarding the time order of the variables. Finally, 
recidivism was measured solely using official records based on convictions. There are several ways to assess recidivism (for example, self-report, arrest, charge) and the use of conviction may reflect extralegal factors (for example, ethnicity, social class, access to quality legal counsel) that come into play regarding court outcomes and a judge's decision to convict rather than 'risk'.

Despite these limitations, the current study sheds light on a relatively unstudied area - comparing dimensions of psychopathic personality via self-report as indicators of recidivism. Considering the fairly consistent findings across a range of measures, the findings from the current study are fairly convincing. It is not too surprising that the factor that best distinguished recidivists and non-recidivists was prior antisocial behavior. Researchers have recognized this as one of the best predictors of recidivism (Cottle et al., 2001). However, the explanatory power of prior behavior is somewhat limited. That is, although prior offending consistently predicts future offending, it does not explain why some individuals are more likely to recidivate than others, or to offend in the first place. Psychopathic traits may help explain unique etiological patterns in offending, identifying a more severe and persistent subgroup of offenders (Frick et al., 2014), although some caution is advised (Edens and Cahill, 2007). Additionally, these factors may be important for developing and tailoring treatment.

\section{Acknowledgements}

We wish to thank the following Portuguese juvenile detention centers for their collaboration: Bela Vista, Mondego, Navarro de Paiva, Olivais, Padre António Oliveira, Santo António, Santa Clara, Prisão-Escola de Leiria.

\section{Funding}

The author(s) disclosed receipt of the following financial support for the research, authorship, and/ or publication of this article: This study was supported by the Portuguese Foundation for Science and Technology (FCT; Grant SFRH/BPD/86666/2012) with co-financing of the European Social Fund (POPH/FSE), the Portuguese Ministry of Education and Science (MEC), and the PT2020 Partnership Agreement (UID/PSI/01662/2013).

\section{ORCID iD}

Pedro Pechorro (iD https://orcid.org/0000-0003-3728-5380

\section{References}

Andershed H (2010) Stability and change of psychopathic traits: What do we know? In Salekin $\mathrm{R}$ and Lynam D (eds) Handbook of Child and Adolescent Psychopathy. New York, NY: Guilford Press, 233-250.

Andrews D and Bonta J (2010) The Psychology of Criminal Conduct (5th edn). New York: Routledge.

Asscher JJ, Van Vugt ES, Stams GJ, Dekovic M, Eichelsheim IV and Yousfi S (2011) The relationship between juvenile psychopathic traits, delinquency and (violent) recidivism: A meta-analysis. Journal of Child Psychology and Psychiatry 52: 1134-1143. doi:10.1111/ j.1469-7610.2011.02412.x. 
Assink M, Van der Put CE, Hoeve M, De Vries SLA, Stams GJJM and Oort FJ (2015) Risk factors for persistent delinquent behavior among juveniles: A meta-analytic review. Clinical Psychology Review 42: 47-61. doi:10.1016/j.cpr.2015.08.002.

Barry CT, Frick PJ and Killian AL (2003) The relation of narcissism and self-esteem to conduct problems in children: A preliminary investigation. Journal of Clinical Child and Adolescent Psychology 32(1): 139-152. doi:10.1207/S15374424JCCP3201_13.

Barry CT, Frick PJ, DeShazo TM, McCoy MG, Ellis M and Loney BR (2000) The importance of callous-unemotional traits for extending the concept of psychopathy to children. Journal of Abnormal Psychology 109: 335-340. doi:10.1037/0021-843X.109.2.335.

Barry C, Grafeman S, Adler K and Pickard J (2007) The relations among narcissism, self-esteem, and delinquency in a sample of at-risk adolescents. Journal of Adolescence 30: 933-942. doi: 10.1016/j.adolescence.2006.12.003.

Blumstein A, Cohen J, Roth JA and Visher CA (1986) Criminal Careers and 'Career Criminals' (Vol. I). Washington, DC: National Academy Press.

Boccaccini MT, Epstein M, Poythress N, Douglas KS and Campbell J (2007) Self-report measures of child and adolescent psychopathy as predictors of offending in four samples of justiceinvolved youth. Assessment 14(4): 361-374. doi: 10.1177/1073191107303569.

Brinkley CA, Schmitt WA, Smith SS and Newman JP (2001) Construct validation of a self-report psychopathy scale: Does Levenson's self-report psychopathy scale measure the same constructs as Hare's psychopathy checklist-revised? Personality and Individual Differences 31: 1021-1038. doi:10.1016/S0191-8869(00)00178-1.

Byrd AL, Kahn RE and Pardini DA (2013) A validation of the inventory of callous-unemotional traits in a community sample of young adult males. Journal of Psychopathology and Behavioral Assessment 35(1): 20-34. doi:10.1007/s10862-012-9315-4.

Caputo A, Frick P and Brosky S (1999) Family violence and juvenile sex offending: The potential role of psychopathic traits and negative attitudes toward women. Criminal Justice and Behavior 26: 338-356. doi:10.1177/0093854899026003004.

Caspi A, Elder EH and Bem DJ (1987) Moving against the world: Life-course patterns of explosive children. Developmental Psychology 23: 308-313. Doi:10.1037/0012-1649.23.2.308.

Colins O, Bijttebier P, Broekaert E and Andershed H (2014) Psychopathic-like traits among detained female adolescents: Reliability and validity of the Antisocial Process Screening Device and the Youth Psychopathic Traits Inventory. Assessment 21: 195-209. doi:10.1177/1073191113481997.

Colins OF, Van Damme L, Andershed H, Fanti KA and DeLisi M (2017) Self-reported psychopathic traits and antisocial outcomes in detained girls: A prospective study. Youth Violence and Juvenile Justice 15: 138-153. doi:10.1177/1541204015619659.

Corrado R, Vincent G, Hart S and Cohen I (2004) Predictive validity of the psychopathy checklist: Youth version for general and violent recidivism. Behavioral Sciences and the Law 22: 5-22. doi:10.1002/bsl.574.

Cottle CC, Lee RJ and Heilbrun K (2001) Prediction of criminal recidivism in juveniles: A metaanalysis. Criminal Justice and Behavior 28: 367-394. doi:10.1177/0093854801028003005.

Dadds MR, Fraser J, Frost A and Hawes DJ (2005) Disentangling the underlying dimensions of psychopathy and conduct problems in childhood: A community study. Journal of Consulting and Clinical Psychology 73(3): 400-410. doi:10.1037/0022-006X.73.3.400.

Douglas KS, Epstein ME and Poythress NG (2008) Criminal recidivism among juvenile offenders: Testing the incremental and predictive validity of three measures of psychopathic features. Law and Human Behavior 32: 423-438. doi:10.1007/s10979-007-9114-8.

Edens JF and Cahill MA (2007) Psychopathy in adolescence and criminal recidivism in young adulthood: Longitudinal results from a multiethnic sample of youthful offenders. Assessment 14: 57-64. doi:10.1177/1073191106290711. 
Edens JF, Campbell JS and Weir JM (2007) Youth psychopathy and criminal recidivism: A meta-analysis of the Psychopathy Checklist measures. Law and Human Behavior 31: 53-75. doi:10.1007/s10979-006-9019-y.

Essau C, Sasagawa S and Frick P (2006) Callous-unemotional traits in community sample of adolescents. Assessment 13: 454-469. doi:10.1177/1073191106287354

Farrington DP (2003) Developmental and life-course criminology: Key theoretical and empirical issues - The 2002 Sutherland Award Address. Criminology 41: 221-225. doi:10.1111/j.1745-9125.2003.tb00987.x.

Feilhauer J and Cima M (2013) Youth psychopathy: Differential correlates of callous-unemotional traits, narcissism, and impulsivity. Forensic Science International 224: 1-7. doi:10.1016/j. forsciint.2012.10.016.

Feilhauer J, Cima M and Arntz A (2012) Assessing Callous-Unemotional traits across different groups of youths: Further cross-cultural validation of the Inventory of CallousUnemotional traits. International Journal of Law and Psychiatry 35: 251-262. doi:10.1016/j. ijlp.2012.04.002.

Fontaine NMG, Rijsdijk FV, McCrory EJP and Viding E (2010) Etiology of different developmental trajectories of callous-unemotional traits. Journal of the American Academy of Child \& Adolescent Psychiatry 49: 656-664. doi:10.1016/j.jaac.2010.03.014.

Forth A, Kosson D and Hare R (2003) Hare Psychopathy Checklist: Youth Version (PCL:YV): Technical manual. Toronto, Ontario, Canada: Multi-Health Systems.

Frick PJ and Ellis M (1999) Callous-unemotional traits and subtypes of conduct disorder. Clinical Child and Family Psychology Review, 2: 149-168. doi:10.1023/A:1021803005547.

Frick P and Hare R (2001) The Antisocial Process Screening Device: Technical Manual. Toronto, Ontario, Canada: Multi-Health Systems.

Frick P and White S (2008) The importance of callous-unemotional traits for developmental models of aggressive and antisocial behavior. Journal of Child Psychology and Psychiatry 49: 359-375. doi:10.1111/j.1469-7610.2007.01862.x.

Frick P, Ray J, Thornton L and Kahn R (2014) Can callous-unemotional traits enhance the understanding, diagnosis, and treatment of serious conduct problems in children and adolescents? A comprehensive review. Psychological Bulletin 140: 1-57. doi:10.1037/a0033076.

Fritz M, Ruchkin V, Kaposov R and Klinteberg B (2008) Antisocial Process Screening Device: Validation on a Russian sample of juvenile delinquents with the emphasis on the role of personality and parental rearing. International Journal of Law and Psychiatry 31: 438-446. doi:10.1016/j.ijlp.2008.08.003.

Gentile B, Miller J, Hoffman B, Reidy D, Zeichner A and Campbell W (2013) A test of two brief measures of grandiose narcissism: The Narcissistic Personality Inventory-13 and the Narcissistic Personality Inventory-16. Psychological Assessment 25(4): 1120-1136. doi: 10.1037/a0033192.

Golmaryami FN and Barry CT (2010) The associations of self-reported and peer-reported relational aggression with narcissism and self-esteem among adolescents in a residential setting. Journal of Clinical Child \& Adolescent Psychology 39(1): 128-133. doi:10.1080/15374410903401203.

Hare R (2003) Hare Psychopathy Checklist-Revised: Technical Manual (2nd edn). Toronto, Canada: Multi-Health Systems.

IBM SPSS (2016) IBM SPSS Statistics Base 24. Chicago, IL: SPSS Inc.

Kahn RE, Byrd AL and Pardini DA (2013) Callous-unemotional traits robustly predict future criminal offending in young men. Law and Human Behavior 37: 87-97. doi:10.1037/b0000003.

Kimonis ER, Kennealy PJ and Goulter N (2016) Does the self-report inventory of callous-unemotional traits predict recidivism? Psychological Assessment 28: 1616-1624. doi:10.1037/ pas0000292. 
Kimonis E, Frick P, Skeem J, Marsee M, Cruise K, Munoz L, . . Morris A (2008) Assessing callous-unemotional traits in adolescent offenders: Validation of the Inventory of Callous-Unemotional Traits. International Journal of Law and Psychiatry 31: 241-252. doi: 10.1016/j.ijlp.2008.04.002.

Kroner DG and Loza W (2001) Evidence for the efficacy of self-report in predicting nonviolent and violent criminal recidivism. Journal of Interpersonal Violence 16: 168-177. doi:10.1177/088626001016002005.

Larsson H, Andershed H and Lichtenstein P (2006) A genetic factor explains most of the variation in the psychopathic personality. Journal of Abnormal Psychology 115: 221-230. doi:10.1037/0021-843X.115.2.221.

Leech N, Barrett K and Morgan G (2015) SPSS for Intermediate Statistics: Use and Interpretation (5th edn). New York: LEA.

Lilienfeld SO and Fowler KA (2007) The self-report assessment of psychopathy: Problems, pitfalls and promises. In: Patrick CJ (ed.) Handbook of Psychopathy. New York, NY: The Guilford Press, 107-132.

Loeber R and Farrington DP (1998) Serious and Violent Juvenile Offenders: Risk Factors and Successful Interventions. Thousand Oaks, CA: Sage Publications.

Loeber R, Farrington DP, Stouthamer-Loeber M, Moffitt TE, Caspi A and Lynam D (2001) Male mental health problems, psychopathy, and personality traits: Key findings from the first 14 years of the Pittsburgh Youth Study. Clinical Child and Family Psychology Review 4: 273297. doi:10.1023/A:1013574903810.

Loney BR, Frick PJ, Clements CB, Ellis ML and Kerlin K (2003) Callous-unemotional traits, impulsivity, and emotional processing in adolescents with antisocial behavior problems. Journal of Clinical Child \& Adolescent Psychology 32(1): 66-80. doi:10.1207/ S15374424JCCP3201_07.

López-Romero L, Romero E and Villar P (2014) Assessing the stability of psychopathic traits from childhood to adolescence: Behavioral and psychosocial outcomes in a six-year follow-up. Personality and Individual Differences 60: S27. doi:10.1016/j.paid.2013.07.037.

Lynam DR (1996) Early identification of chronic offenders: Who is the fledgling psychopath? Psychological Bulletin 120: 209-234. doi:10.1037/0033-2909.120.2.209.

Maltz MD (1984) Recidivism. Orlando, FL: Academic Press.

Moffitt TE (1993) Adolescence-limited and life-course-persistent antisocial behavior: A developmental taxonomy. Psychological Review 100: 674-701. doi:10.1037/0033-295X.100.4.674.

Murrie DC, Cornell DG, Kaplan S, McConville D and Levy-Elkon A (2004) Psychopathy scores and violence among juvenile offenders: A multi-measure study. Behavioral Sciences \& the Law 22(1): 49-67. doi:10.1002/bs1.573.

Neumann C, Wampler M, Taylor J, Blonigen D and Iacono W (2011) Stability and invariance of psychopathic traits from late adolescence to young adulthood. Journal of Research in Personality 45: 145-152. doi:10.1016/j.jrp.2010.12.003.

Olver ME, Stockdale KC and Wormith JS (2009) Risk assessment with young offenders: A meta-analysis of three assessment measures. Criminal Justice and Behavior 36: 329-353. doi:10.1177/0093854809331457.

Patton J, Stanford M and Barratt E (1995) Factor structure of the Barratt Impulsiveness Scale. Journal of Clinical Psychology 51: 768-774. doi:10.1002/1097-4679.

Payne J (2007) Recidivism in Australia: Findings and Future Research. Research and Public Policy Series No. 80, Australian Institute of Criminology.

Pechorro P, Hidalgo V, Nunes C and Jiménez L (2016) Confirmatory factor analysis of the Antisocial Process Screening Device: Self-report among incarcerated male juvenile offend- 
ers. International Journal of Offender Therapy and Comparative Criminology 60: 18561872. doi:10.1177/0306624X15588903.

Pechorro P, Maroco J, Ray J and Gonçalves R (2015) Psychometric properties of the Barratt Impulsiveness Scale version 11 among a Portuguese sample of incarcerated juvenile offenders. Psychology, Crime \& Law 21: 854-870. doi:10.1080/1068316X.2015.1054386.

Pechorro P, Ray J, Gonçalves R and Jesus S (2017) The Inventory of Callous-Unemotional Traits: Psychometric properties among referred and non-referred Portuguese female juveniles. International Journal of Law and Psychiatry 54: 67-75. doi:10.1016/j.ijlp.2017.05.002.

Pechorro P, Gentile B, Ray J, Nunes C and Gonçalves R (2016) Adaptation of the Narcissistic Personality Inventory among Portuguese juvenile offenders. Psychology, Crime \& Law 22: 495-511. doi:10.1080/1068316X.2016.1168421.

Pechorro P, Maroco J, Gonçalves R, Nunes C and Jesus S (2014) Psychopathic traits and age of crime onset in male juvenile delinquents. European Journal of Criminology 11: 288-302. doi: $10.1177 / 1477370813495759$.

Pechorro P, Ray J, Barroso R, Maroco J and Gonçalves R (2016) Validation of the Inventory of Callous-Unemotional Traits among a Portuguese sample of detained juvenile offenders. International Journal of Offender Therapy and Comparative Criminology 60: 349-365. doi: 10.1177/0306624X14551256.

Pechorro P, Ayala-Nunes L, Ray J, Nunes C and Gonçalves R (2016) Psychometric properties of the Portuguese version of the Barratt Impulsiveness Scale - 11 among a school sample of male and female adolescents. Journal of Child and Family Studies 25: 2753-2764. doi:10.1007/ s10826-016-0453-2.

Piquero AR, Farrington DP and Blumstein A (2003) The criminal career paradigm. In: Tonry M (ed.) Crime and Justice (Vol. 20). Chicago: University of Chicago Press, 359-506.

Piquero AR, Farrington DP, Fontaine NMG, Vincent G, Coid J and Ullrich S (2012) Childhood risk, offending trajectories, and psychopathy at age 48 years in the Cambridge Study in Delinquent Development. Psychology, Public Policy, and Law 18: 577-598. doi:10.1037/ a0027061.

Poythress N, Dembo R, Wareham J and Greenbaum P (2006) Construct validity of the youth psychopathic features inventory (YPI) and the antisocial process screening device (APSD) with justice involved adolescents. Criminal Justice and Behavior 33(1): 26-55. doi:10.1177/0093854805282518.

Raskin R and Terry H (1988) A principal-components analysis of the Narcissistic Personality Inventory and further evidence of its construct validity. Journal of Personality and Social Psychology 54: 890-902. doi:10.1037/0022-3514.54.5.890.

Ray J, Pechorro P and Gonçalves R (2016) A comparison of self-report measures of callous-unemotional traits among incarcerated youth: Associations with aggression, conduct disorder, and offending behavior. Criminal Justice and Behavior 43: 1293-1309. doi: $10.1177 / 0093854815628027$.

Salekin R (2008) Psychopathy and recidivism from mid-adolescence to young adulthood: Cumulating legal problems and limiting life opportunities. Journal of Abnormal Psychology 117: 386-395. doi:10.1037/0021-843X.117.2.386.

Schmidt F, McKinnon L, Chattha HK and Brownlee K (2006) Concurrent and predictive validity of the Psychopathy Checklist: Youth Version across gender and ethnicity. Psychological Assessment 18: 393-401. doi:10.1037/1040-3590.18.4.393.

Schwalbe CS (2007) Risk assessment for juvenile offenders: A meta-analysis. Law and Human Behavior 31: 449-462. doi:10.1007/s10979-006-9071-7. 
Simões MR (2000) Investigações no âmbito da Aferição Nacional do Teste das Matrizes Progressivas Coloridas de Raven [Investigations in the context of the national standardization of the Raven Coloured Progressive Matrices test]. Lisbon: Fundação Calouste Gulbenkian.

Stanford M, Mathias C, Dougherty D, Lake S, Anderson N and Patton J (2009) Fifty years of the Barratt Impulsiveness Scale: An update and review. Personality and Individual Differences 47: 385-395. doi:10.1016/j.paid.2009.04.008.

Thomson ND, Towl GJ and Centifanti LCM (2015) The habitual female offender inside: How psychopathic traits predict chronic prison violence. Law and Human Behavior 40: 257-269. doi:10.1037/lhb0000178.

Vasconcelos A, Malloy-Diniz L and Correa H (2012) Systematic review of psychometric properties of Barratt Impulsiveness Scale version 11 (BIS-11). Clinical Neuropsychiatry 9: 61-74. doi:10.1590/1516-4446-2014-1599.

Vitacco MJ, Caldwell MF, Van Rybroek GJ and Gabel J (2007) Psychopathy and behavioral correlates of victim injury in serious juvenile offenders. Aggressive Behavior 33: 537-544. doi:10.1002/ab.20211.

Vitacco MJ, Rogers R and Neumann CS (2003) The antisocial process screening device: An examination of its construct and criterion-related validity. Assessment 10: 143-150. doi: 10.1177/1073191103010002005.

White J, Moffitt T, Caspi A, Jeglum-Bartusch D, Needles D and Stouthamer-Loeber M (1994) Measuring impulsivity and examining its relation to delinquency. Journal of Abnormal Psychology 103: 192-205. doi:10.1037/0021-843X.103.2.192.

Zara G and Farrington DP (2016) Criminal Recidivism: Explanation, Prediction and Prevention. New York: Routledge. 